\title{
Atividade de comunicação e trabalho dos jornalistas
}

\section{Roseli Figaro}

\section{Resumo}

Este artigo discute o mundo do trabalho dos jornalistas de São Paulo a partir de pesquisa realizada entre 2009 e 2012 pelo Centro de Pesquisa em Comunicação e Trabalho da ECA-USP ${ }^{1}$. A investigação tem como aporte teórico-metodológico o binômio comunicação e trabalho, ou seja, compreende comunicação e trabalho como unidade constitutiva da atividade humana, capaz de revelar os valores com os quais se constrói sociedade. Com a triangulação de métodos quantitativos e qualitativos, a pesquisa revela o perfil dos jornalistas de São Paulo e seus pontos de vista sobre 0 trabalho.

\section{Palavras-Chave}

Comunicação e trabalho. Jornalistas.

Tecnologias. Atividade.
Roseli Figaro | fígaro@uol.com.br Professora livre-docente no Programa de Pós-Graduação em Ciências da Comunicação da Escola de Comunicações e Artes, Universidade de São Paulo (USP).

\section{Introdução}

0 binômio comunicação e trabalho é uma proposta teórico-metodológica que trata da centralidade da categoria trabalho a partir do campo da comunicação. Afirma-se que tal centralidade se dá, sobretudo, devido à incorporação da comunicação como lógica organizativa dos processos produtivos e devido à presença das tecnologias de informação e de comunicação no mundo do trabalho. Para além da determinação econômica, o trabalho constrói as relações entre as pessoas na sociedade. Ele é fonte de criação, ordenação e hierarquização dos valores sociais e dos laços de sociabilidade.

Para aprofundar essa discussão, problematizase a atividade humana como manifestação em forma de comunicação e de trabalho. Essa construção teórica propicia entender a presença das tecnologias e seus usos no cotidiano, e analisar como a comunicação é engendrada aos modelos produtivos, bem como analisar quais são os valores éticos e os pontos de vista ideológicos a partir dos quais as 
pessoas fazem suas escolhas no mundo do trabalho.

A partir desses pressupostos, este artigo traz para discussão o mundo do trabalho dos jornalistas.

\section{Comunicação e atividade humana de trabalho}

A atividade humana de trabalho interessa particularmente ao campo científico da comunicação. Isso porque ela corrobora que se entenda 0 conceito de comunicação de maneira mais ampla, como constitutivo do humano. A comunicação não fica restrita a objeto de estudo vinculado aos aparatados dos meios de comunicação, sejam eles tradicionais ou digitais.

Quando se restringe o objeto da comunicação às mídias, atende-se pontualmente a questões que dizem respeito à determinação tecnológica no estudo da comunicação. Nega-se lhe a potencialidade de campo do conhecimento capaz de tratar de problemas como, por exemplo, aqueles relativos às relações de comunicação na sociedade entre os diferentes grupos, identidades e classes; ou aos processos produtivos, à atividade industriosa. A abordagem da atividade de comunicação e de trabalho dá destaque à comunicação humana, porque, do ponto de vista epistemológico, prioriza o estudo das relações de comunicação que se dão no percurso entre os saberes instituídos (norma, prescrição) e os saberes da experiência (inédito da atividade concreta) (SCHWARTZ, DURRIVE, 2007).

Estudar a comunicação como aspecto inerente à atividade humana, capaz de revelar as complexas relações que se estabelecem no mundo do trabalho, traz para a área de conhecimento da comunicação uma gama de novos temas de pesquisa. Sobretudo, dá ao conceito de comunicação um caráter ontológico, no sentido da ontologia do ser social que Marx discute nos Manuscritos econômicos filosóficos, de 1844, ou seja, aquele da unidade indissolúvel entre subjetividade e objetividade, presente na atividade matriz de sociabilidade, 0 trabalho.

Entende-se que a relação entre 0 indivíduo/social e os meios de vida se dá pela atividade humana de trabalho no âmbito das relações de comunicação. A comunicação é uma conquista da espécie humana, efetivada pela condição do homem de sobrepor-se, por meio de sua atividade de trabalho, às condições da natureza. É a atividade de comunicação e de trabalho o material objetivo, com o qual se fabrica a realidade humana. Nesse sentido, a proposta de estudo que articula a atividade de comunicação e de trabalho opõe-se à separação entre atividade humana e história; entre atividade humana e condições materiais e culturais da existência da sociedade. 0 inédito da atividade, a sua impossível antecipação, 
articula-se dialeticamente com o conhecido, 0 estabelecido, o prescrito da norma ou das regras e forças estabelecidas pelo poder hegemônico em dada sociedade.

\section{Tecnologias, comunicação e atividade humana}

Não é possível dissociar o mundo do trabalho das tecnologias de informação e de comunicação. Quando nos reportamos às tecnologias de informação e de comunicação, chamamos a atenção para as apropriações que se faz delas como produtos da atividade humana. Elas devem ser problematizadas no nível dos objetos empíricos concretos e consideradas no percurso de artefato a instrumento. As formas concretas de apropriação dos artefatos e os valores que conformam as escolhas para seu uso são revelados na atividade de trabalho.

Na mesma linha de Vigotski, Leontiev (1976) considera a atividade mediada por artefatos como preponderante na formação da psique humana.

0 trabalho e a comunicação são os fundamentos dessa formação. Visto que um novo artefato não é imediatamente e indiscriminadamente incorporado pelo sujeito, mas depende da articulação com a atividade concreta desse sujeito. Há a necessidade do uso, de esquemas de apropriação pessoal, há a manifestação da plenitude do sujeito em atividade. Daí Folcher e Rabardel (2007) classificarem o instrumento como "unidade mista", por um lado, um artefato material ou simbólico, produzido pela cultura; por outro, esquemas de utilização associados, resultado de construção própria do sujeito.

Dierkes, Hofmann e Marz (2000) afirmam que as tecnologias são marcadas pelo contexto em que são elaboradas e exploradas. Esses usos mostram quais são os valores e as opções que articulam fatores econômicos, sociais, culturais, políticos e organizacionais. Se há valores que orientam as opções sobre 0 desenvolvimento e os usos das tecnologias, esses valores estão imersos no sistema complexo de relações culturais, econômicas e políticas. 0 novo na apropriação de uma tecnologia, de um processo produtivo sempre está marcado por um antes, um histórico que 0 engendrou. 0 mesmo ocorre com os processos comunicacionais.

Scolari (2008) destaca o contexto de existência das novas tecnologias no ambiente sociotécnico ${ }^{2}$ de concentração vertical e horizontal das empresas de comunicação. Assim, se por um lado, as tecnologias digitais proporcionam inovação e transgressão dos modelos tradicionais de relação entre produção e consumo, por outro, as organizações buscam

"0 desenvolvimento da Escola Sócio-Técnica teve início no Instituto Tavistock de Londres, nos anos 50, sob a coordenação de E. Trist, F. Emery, Rice, Jacques, Hall e Bramfort. [...] 0 modelo sócio-técnico parte do pressuposto de que todo sistema tem entrada, processamento e saída. Assim, a organização enquanto sistema de produção recebe (importa) matéria-prima (energia, informação e recursos) do meio ambiente, e, processa essas matérias-prima, através de uma conversão, em energia, informações, produtos acabados." (GOMES; BORELLI; NAZARÉ, 2009). 
formas de enquadramento das novidades sem romper com os fundamentos que as estruturam.

Consoante à preocupação de Scolari, Castells, em Comunicación y poder (2010, p. 116), ressalta que "As maiores empresas midiáticas têm mais proriedades do que nunca e também mais conteúdo próprio[... $]^{\text {”3. }}$. Ou seja, as redes sociais, 0 teletrabalho e a informação em tempo real dialogam com o novo, com o futuro na mesma medida em que foram apropriados pelas condições objetivas que nos fazem estar no agora de um sistema econômico cada vez mais centralizador. Nesse sentido, Eli Pariser (2012) chama a atenção para o controle que 0 Google passa a deter sobre os dados das pessoas em todo o mundo. Dados que lotam a prateleira da empresa como mercadoria a ser negociada no mercado publicitário. Mais do que isso, Pariser (2012, p. 36) afirma que "Hoje em dia, o Google monitora todo e qualquer sinal que consiga obter sobre nós". Assim, o paradoxo que se apresenta é o do controle institucional e da individualização de acessos como faces de uma mesma lógica de funcionamento e estrutura. São esses aspectos de contraposição de forças que os estudos do campo da comunicação, a partir do binômio comunicação e trabalho, permitem colocar em evidencia.

\section{Comunicação no mundo do trabalho}

Outro aspecto da temática em discussão é aquele das relações de comunicação no mundo do trabalho. Essas relações, quando consideradas em seu potencial de pluralidade e diversidade, podem revelar tendências e identificar problemas para além dos interesses do controle da organização da produção.

Por outro lado, a comunicação da organização (empresa) está sempre demarcada, limitada pela finalidade dela mesma, ou seja, sob o controle de uma racionalidade que visa à economia e à eficiência, restrita à hierarquia da autoridade e ao organograma de departamentos, postos e funções.

Essas duas instâncias - a instituição empresa e 0 mundo do trabalho -, com enunciadores diferentes e finalidades também diferentes, convivem na atividade real do mundo do trabalho. Há, no entanto, um elemento novo vislumbrado devido ao avanço tecnológico e à mudança do modelo de produção, e esse elemento novo é a comunicação como ferramenta de controle do trabalho.

0 relatório do Commissariat Général du Plan, do Ministère de l’industrie, França, em 1990, denominado L’Usine du futur. L'entreprise communicante et intégrée, (Paris, 1990) dá a direção para o que se denominará "favorecer a circulação ótima da informação", "perfeita comunicação", "integração e favorecimento da comunicação" ou seja, uma prescrição nacional para a regulação integrada da comunicação na empresa. Observe-se 
no título: a empresa comunicante. Essa diretiva não está restrita e nem mesmo é invenção francesa, é uma orientação do "novo" sistema de racionalização do processo produtivo, "a organização comunicante responde assim aos critérios econômicos de eficácia" (OLIVESI, 2006, p. 64).

\section{A organização comunicante apropria-se dos} saberes do mundo do trabalho para domesticá-los e/ou transformá-los em equipamentos, máquinas, software e processos. Essa é a finalidade da racionalização do trabalho. Processo que se amplia com as novas tecnologias, e cuja prescrição deriva daquela instituída pela Organização Científica do Trabalho desde o início do século XX. Jaron Lanier (2010, p. 20), no livro Gadget, sintetiza a pretensão da organização como controle ao expor que: "Basta um pequeno grupo de engenheiros para criar uma tecnologia capaz de moldar todo o futuro da experiência humana com uma incrível velocidade."

Assim as políticas de comunicação nas organizações podem ser sintetizadas como intenção de manipulação dos saberes do trabalho. Sobretudo, é um apelo para que se transforme a gestão de si mesmo em processo a ser conhecido por outros e sistematizado pela empresa em proveito do capital.

São esses os pressupostos teóricos que se aplicam à pesquisa 0 perfil dos jornalistas e os discursos sobre o jornalismo. Um estudo das mudanças no mundo do trabalho dos jornalistas de São Paulo (2009-2012), realizada com apoio da Fundação de Apoio a Pesquisa do Estado de São Paulo

(Fapesp), e que se passa a relatar.

\section{Comunicação e trabalho dos jornalistas}

No Brasil, a prática profissional do jornalismo consolidou-se na segunda metade do século XX. Empresas e jornalistas profissionalizaram-se para atender a demandas vinculadas a relações políticas e comerciais no âmbito do Estado, das grandes empresas anunciantes e da geopolítica internacional. Com 0 advento da informatização e das novas mídias, 0 jornalismo e 0 jornalista enfrentam desafios.

0 que se pode afirmar sobre quem faz 0 jornalismo e sobre como esse fazer, suas normas e rotinas produtivas, está delimitado pela lógica da grande empresa? Como o jornalista, nas dramáticas da atividade de trabalho (SCHWARTZ, DURRIVE, 2007), enfrenta os desafios cotidianos do exercício profissional?

Muniz Sodré, em A narração do fato, 2009, marca sua preocupação com a narrativa jornalística. Ele percorre o caminho de sua reflexão mostrando-nos as pertinências e as irreverências entre fato, notícia e acontecimento. Sobretudo destaca a narrativa jornalística por sua essencialidade de mercadoria.

Muniz dá pistas importantes para que se problematize 0 universo do jornalismo e dos jornalistas. Afirma Muniz Sodré (2009, p. 194): 
"[...] a informação contemporânea implica outro tipo de valor: transparência, ao invés de densidade simbólica." Ou seja, quanto mais se dissimula ou se apagam os modos de como o relato é produzido, construído, elaborado maior é sua força e aparente transparência. Abreu (2002, p. 35) afirma que "[...] são a competitividade entre os vários tipos de mídia e a disputa pelo mercado as responsáveis pelo comportamento dos jornalistas na atualidade".

Esses aspectos também foram verificados pela pesquisa 0 perfil dos jornalistas e os discursos sobre 0 jornalismo. Um estudo das mudanças no mundo do trabalho dos jornalistas de São Paulo (2009-2012). 0 objetivo da pesquisa foi 0 de realizar um levantamento sobre 0 perfil dos jornalistas profissionais em São Paulo; e conhecer o ponto de vista desse profissional sobre 0 seu trabalho. 0 perfil dos jornalistas abrange dados sobre faixa etária, escolaridade, vínculo empregatício, relações de trabalho, dados socioeconômicos e de consumo cultural. A estratégia da pesquisa tem como referência a triangulação metodológica (JENSEN;

JANKOWSKI, 1993), com os instrumentos de pesquisa: questionário quantitativo de múltipla escolha, entrevista em profundidade e grupo de discussão. A triangulação metodológica também se deu na composição das amostras da pesquisa. Foram compostas quatro amostras a partir do critério de vínculo empregatício, buscando-se jornalistas em redes profissionais na internet, com diferentes vínculos e trabalhando em diferentes mídias; profissionais associados do Sindicato dos Jornalistas no Estado de São Paulo; e jornalistas com emprego fixo em uma grande empresa editorial de São Paulo. 0 desenho da amostragem da pesquisa está sintetizado no Quadro 1.

Como aponta 0 Quadro 1, a amostra Grupo A, composta por jornalistas com diferentes tipos de vínculos empregatícios, foi montada como pré-teste para o questionário fechado de múltipla escolha, composto por perguntas relativas a três grandes temas: dados pessoais, dados profissionais, acesso a meios de comunicação e consumo cultural.

Com o retorno das respostas dos jornalistas contatados via rede social profissional, ampliouse 0 número de perguntas do questionário, mantendo-se a mesma estrutura temática, $\mathrm{e}$ buscou-se 0 apoio do Sindicato dos Jornalistas Profissionais do Estado de São Paulo, para dar prosseguimento à pesquisa por meio dos sócios do sindicato com endereço eletrônico. Depois de tratada a base de associados, enviou-se mensagem convite aos jornalistas sócios para participarem da pesquisa. As respostas dos associados ao questionário permitiram verificar que o perfil dos jornalistas sócios é bastante diferente dos jornalistas do pré-teste. A partir daí, decidiu-se pela ampliação da pesquisa com a coleta de dados a partir de outras fontes. Recorreu-se à amostra de jornalistas de empresa editorial de São Paulo que haviam respondido 
a questionário semelhante em 2007. Também se recorreu a redes de contatos de freelancers "Freela.com.br" e "Clicfólio", como forma de, por meio de redes sociais profissionais, específicas para jornalistas, enviar convites de participação na pesquisa. Todos os participantes, de todas as quatro amostras, receberam uma mensagem convite para participar da pesquisa, e por meio de uma senha, tiveram acesso ao questionário que, depois de respondido, era enviado para o banco de dados do Centro de Pesquisa em Comunicação e Trabalho. As amostras consolidadas estão no Quadro 2.
Como se vê no Quadro 2, foram enviados 3278 questionários a jornalistas e 538 questionários respondidos foram consolidados. Na etapa qualitativa, foram realizadas 20 entrevistas com jornalistas selecionados a partir dos critérios de perfil verificados na fase quantitativa. 0 mesmo critério orientou a composição de dois grupos de discussão. Um grupo foi composto por jornalistas com diferentes vínculos de trabalho e 0 segundo grupo foi composto por jornalistas freelancers. As técnicas de composição, acompanhamento do grupo de discussão foram adotadas conforme orienta (BARBOUR, 2009).

Quadro 1: Composição da amostra da pesquisa

\begin{tabular}{|c|c|c|c|c|}
\hline Amostra & $\begin{array}{c}\text { Ano do } \\
\text { questionário }\end{array}$ & Seleção & Vínculo empregatício & Espaço de trabalho \\
\hline $\begin{array}{l}\text { Grupo A } \\
\text { (Pré-teste) }\end{array}$ & 2009 & $\begin{array}{l}\text { selecionados de } \\
\text { maneira aleatória via } \\
\text { rede social de contato } \\
\text { profissional }\end{array}$ & $\begin{array}{l}\text { profissionais de } \\
\text { diferentes vínculos } \\
\text { empregatícios } \\
\text { (freelancer, contrato, } \\
\text { pessoa jurídica, } \\
\text { cooperativado, etc. }\end{array}$ & $\begin{array}{l}\text { trabalhando em } \\
\text { diferentes mídias }\end{array}$ \\
\hline $\begin{array}{c}\text { Grupo B } \\
\text { (Sócios do Sindicato } \\
\text { dos Jornalistas no } \\
\text { Estado de São Paulo) }\end{array}$ & 2009 & $\begin{array}{l}\text { dados fornecidos pelo } \\
\text { Sindicato }\end{array}$ & $\begin{array}{l}\text { jornalistas com } \\
\text { diferentes vínculos } \\
\text { empregatícios e } \\
\text { funções }\end{array}$ & $\begin{array}{c}\text { trabalhando em } \\
\text { diferentes mídias e } \\
\text { locais }\end{array}$ \\
\hline $\begin{array}{c}\text { Grupo C } \\
\text { (Empresa Editorial) }\end{array}$ & 2007 & $\begin{array}{l}\text { selecionados a } \\
\text { partir da função que } \\
\text { exerciam na empresa }\end{array}$ & $\begin{array}{l}\text { jornalistas } \\
\text { empregados em } \\
\text { empresa de } \\
\text { comunicação }\end{array}$ & $\begin{array}{c}\text { trabalhando em } \\
\text { revistas dessa mesma } \\
\text { empresa }\end{array}$ \\
\hline $\begin{array}{c}\text { Grupo D } \\
\text { (Freelancers) }\end{array}$ & 2010 & $\begin{array}{l}\text { a partir de redes } \\
\text { de contatos de } \\
\text { freelancers ("Freela. } \\
\text { com.br" e "Clicfólio") e } \\
\text { pela técnica da bola- } \\
\text { de-neve" ou snowball } \\
\text { (Bernard, 1996) }\end{array}$ & $\begin{array}{l}\text { Jornalistas sem } \\
\text { vínculo empregatício } \\
\text { (freelancers) }\end{array}$ & $\begin{array}{l}\text { trabalhando em } \\
\text { diferentes mídias/ } \\
\text { empresas }\end{array}$ \\
\hline
\end{tabular}


Quadro 2: Composição das amostras quantitativas e qualitativas da pesquisa

\begin{tabular}{|c|c|c|c|}
\hline \multirow{2}{*}{$\begin{array}{c}\text { Composição das amostras } \\
\text { da pesquisa }\end{array}$} & \multicolumn{2}{|c|}{ Fase quantitativa } & Fase qualitativa \\
\cline { 2 - 4 } & $30\left(^{\star \star}\right)$ & $26-86 \%$ & Seleção* \\
\hline $\begin{array}{c}\text { Grupo A - Jornalistas } \\
\text { captados por redes sociais } \\
\text { (pré-teste) }\end{array}$ & 2954 & $340-13 \%$ & $22(7,6 \%)$ \\
\hline $\begin{array}{c}\text { Grupo B - Sindicato dos } \\
\text { Jornalistas do Estado de SP }\end{array}$ & $\left.738 / 142^{(\star \star}\right)$ & $82-11 / 59 \%$ & $9(5 \%)$ \\
\hline Grupo C - Empresa Editorial & $\left.152^{\star * \star \star}\right)$ & $90-59 \%$ & $4(4,8 \%)$ \\
\hline $\begin{array}{c}\text { Grupo D - Jornalistas } \\
\text { Freelancers da cidade de SP }\end{array}$ & 3278 & $538-16,41 \%$ & $5(5,5 \%)$ \\
\hline Total & & $20(5,2 \%)$ \\
\hline
\end{tabular}

\section{Atividade de trabalho dos jornalistas mostra-se em risco}

As pesquisas revelam a precarização das relações de trabalho (FIGARO, 2008, 2012; LIMA, 2010, GROHMANN, 2012) bem como a intensificação do ritmo de atividade exigida no âmbito do exercício profissional, prejudicando a qualidade de vida dos profissionais (HELOANI, 2005). Indicam também a preocupação dos comunicadores com o futuro da prática jornalística, principalmente, aquela desenvolvida em jornais, revistas e televisão.

Os resultados apontam as mudanças no perfil do jornalista profissional: são jovens, brancos, de classes médias, mulheres a maioria sem filhos, multiplataformas, vínculo de emprego precário, com curso superior completo e com especialização em nível de pós-graduação. A maioria se formou de um a até 15 anos, ou seja, entrou na profissão quando as reformas trazidas pelo computador e a internet estavam se efetivando. 0s jovens jornalistas entraram no mercado com um novo desafio pela frente, entender o que era aquilo que estava acontecendo com as novas tecnologias de informação e de comunicação. Os freelancers trabalham em período integral, para vários lugares, trabalham sozinhos em casa. Começam a pensar como novos empreendedores, aplicam os conhecimentos do jornalismo em outras atividades, desde fazer a revisão de um trabalho acadêmico até vender um pacote de assessoria de comunicação a um político. Vão em busca do cliente.

A reestruturação produtiva ocorrida no mundo do trabalho, principalmente a partir dos anos 1990, transformou as relações de trabalho. Foi a partir dessa década que aumentou o número de jornalistas contratados sem registro em carteira profissional, abrindo caminho para 0 surgimento de novas formas de contratação, como a terceirização, contratos de trabalho por 
tempo determinado, contrato de Pessoa Jurídica (PJ), cooperados e freelancers, entre outros.

São os jovens, não sindicalizados, que mantêm vínculos precários, trabalham entre oito e dez horas por dia e em ritmo acelerado. 0 fato de a maioria dos freelancers receberem o pagamento a partir de nota fiscal fornecida por um terceiro e trabalharem no setor de revista e internet dá indicações claras de onde estão os problemas contratuais. 0s gráficos 1 e 2 demonstram que em todos os grupos de amostras de jornalistas trabalham-se de oito a doze horas por dia e,

Gráfico 1- Jornada de trabalho
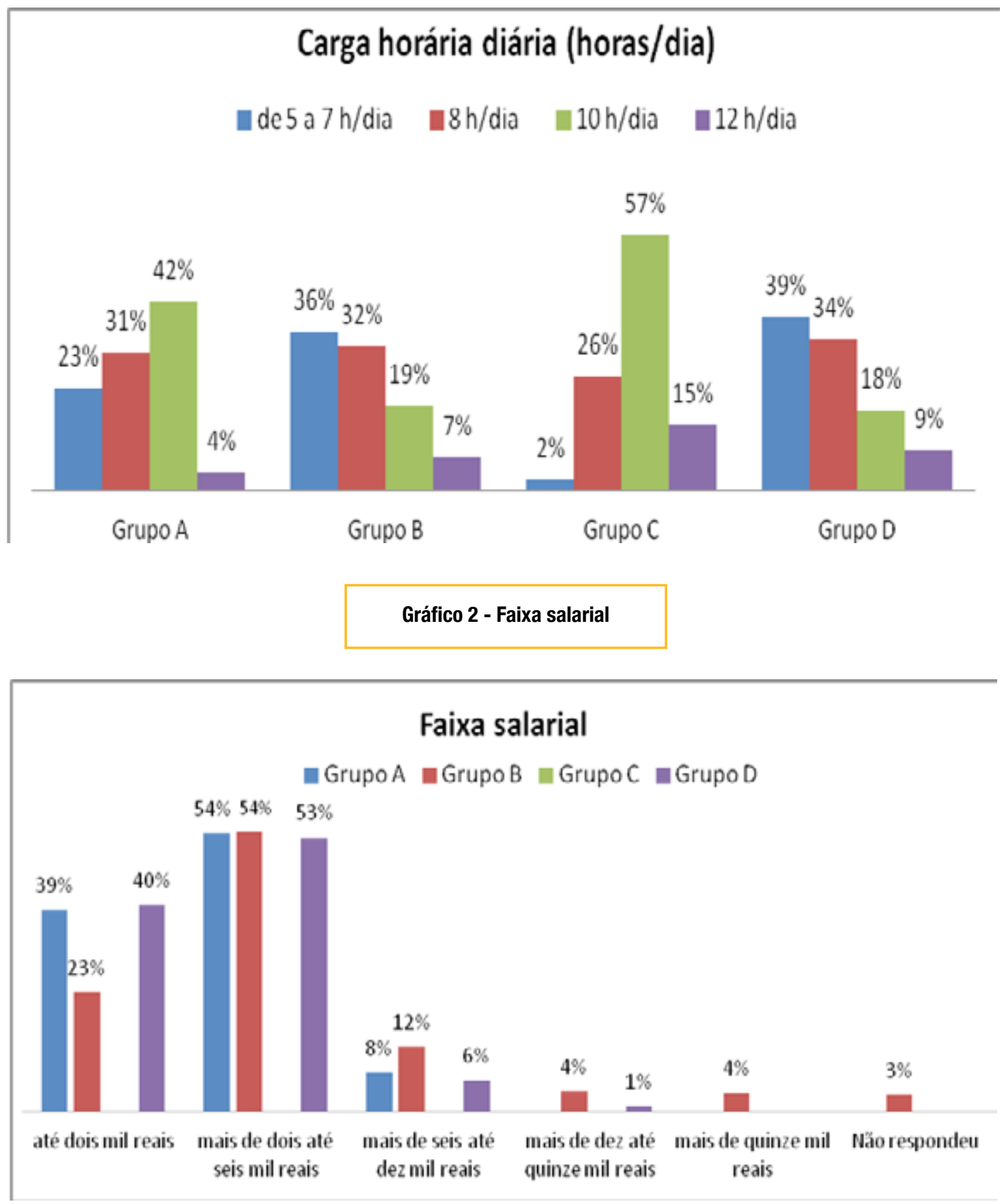


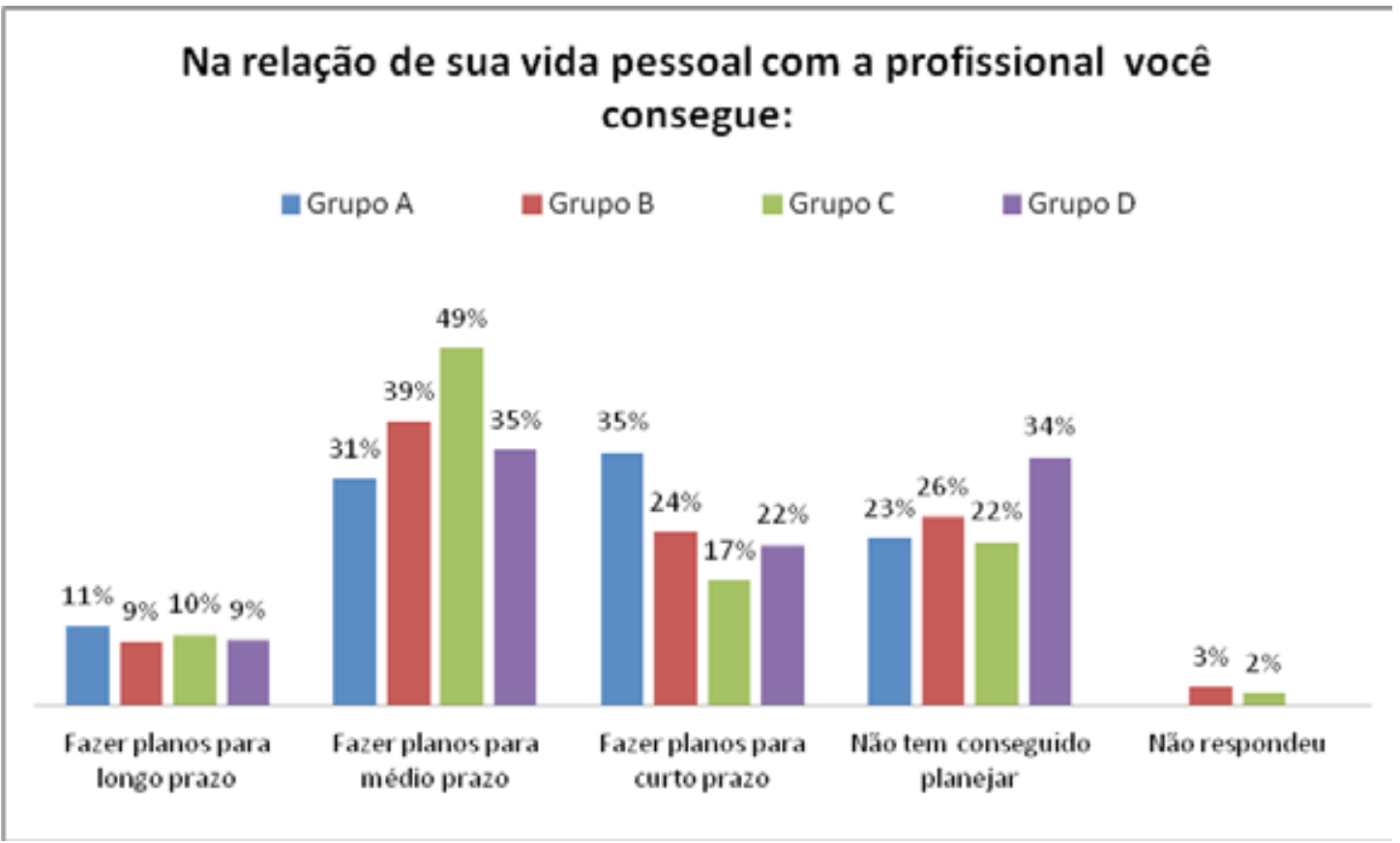

quanto aos salários, entre todos os grupos de jornalistas a maioria recebe entre dois e seis mil reais.

São os mais jovens que não conseguem planejar a vida fora do curto prazo, vão em busca do cliente e consideram a informação como um produto. $\mathrm{Ou}$ seja, possuem um perfil profissional deslocado de valores coletivos; são individualistas e muito mais preocupados com o negócio, meio de vida. Inclusive, estes valores individualistas se ajustam ao que Boltanski e Chiapello (2009) chamam de "novo espírito do capitalismo", pois as instâncias coletivas de trabalho perdem força, havendo instâncias individuais em rede. Segundo Bernardo (2009, p. 93-94), "[...] as empresas estabelecem uma relação ambígua com seus empregados, pois os convidam a integrarem equipes/grupos de trabalho ao mesmo tempo em que lhes impõe relações de trabalho individualizadas" e, acrescentem-se, precárias.

A chamada "flexibilidade" acaba por transferir aos trabalhadores o peso das incertezas do mercado. Como mão de obra maleável, seja em termos de horário, de jornada de trabalho ou de vínculo empregatício (como empregos temporários, precários ou trabalho autônomo), esses profissionais não têm podido planejar suas vidas em termos econômicos e em termos afetivos. 0 único grupo que consegue planejar a vida pessoal e profissional no médio prazo é aquele com emprego fixo.

Como demonstram os gráficos 4 e 5, a captação de clientes e a receita publicitária são os fatores externos que influenciam o jornalismo. A opinião 


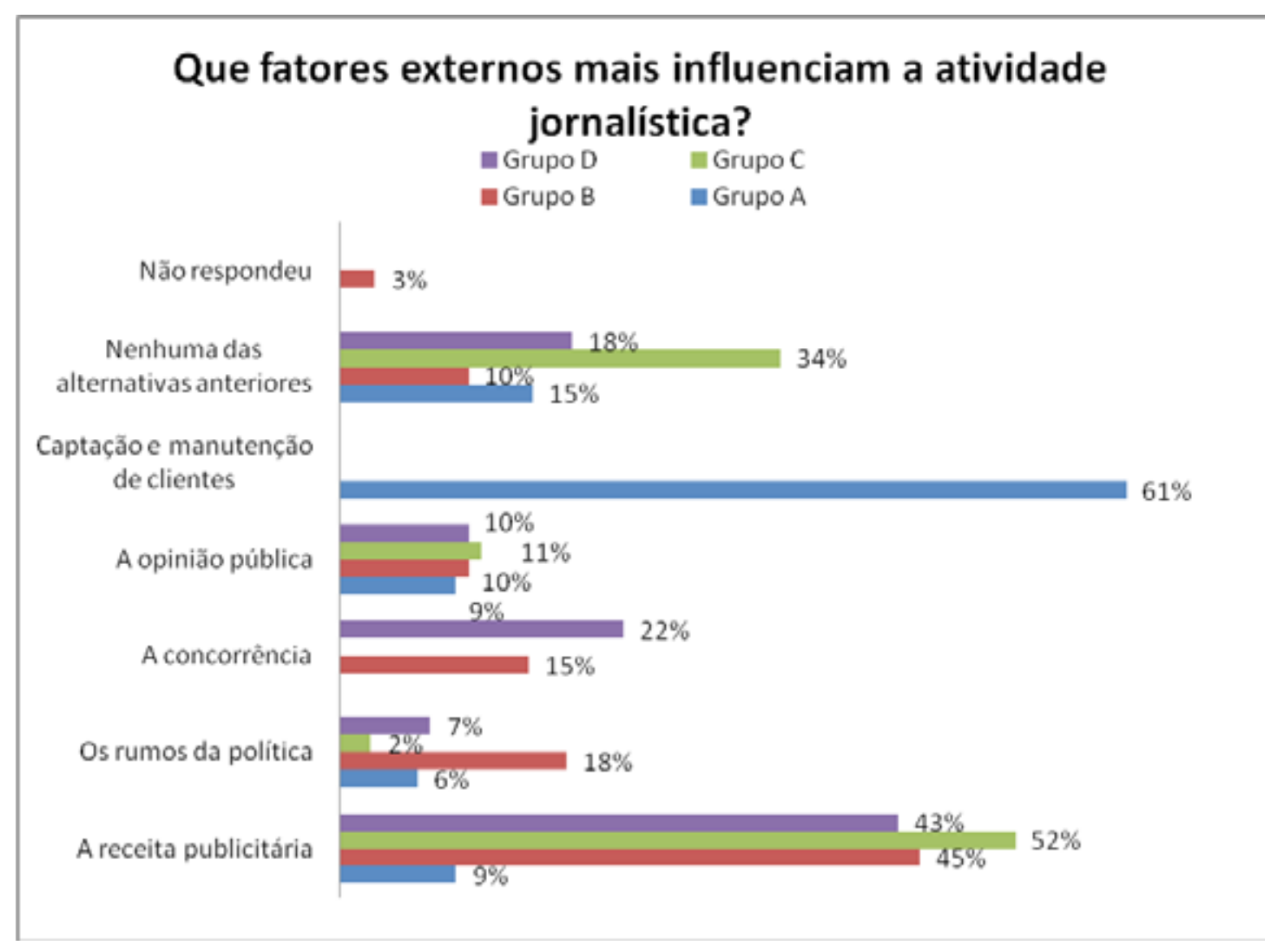

Gráfico 5 - Importância dos meios de comunicação

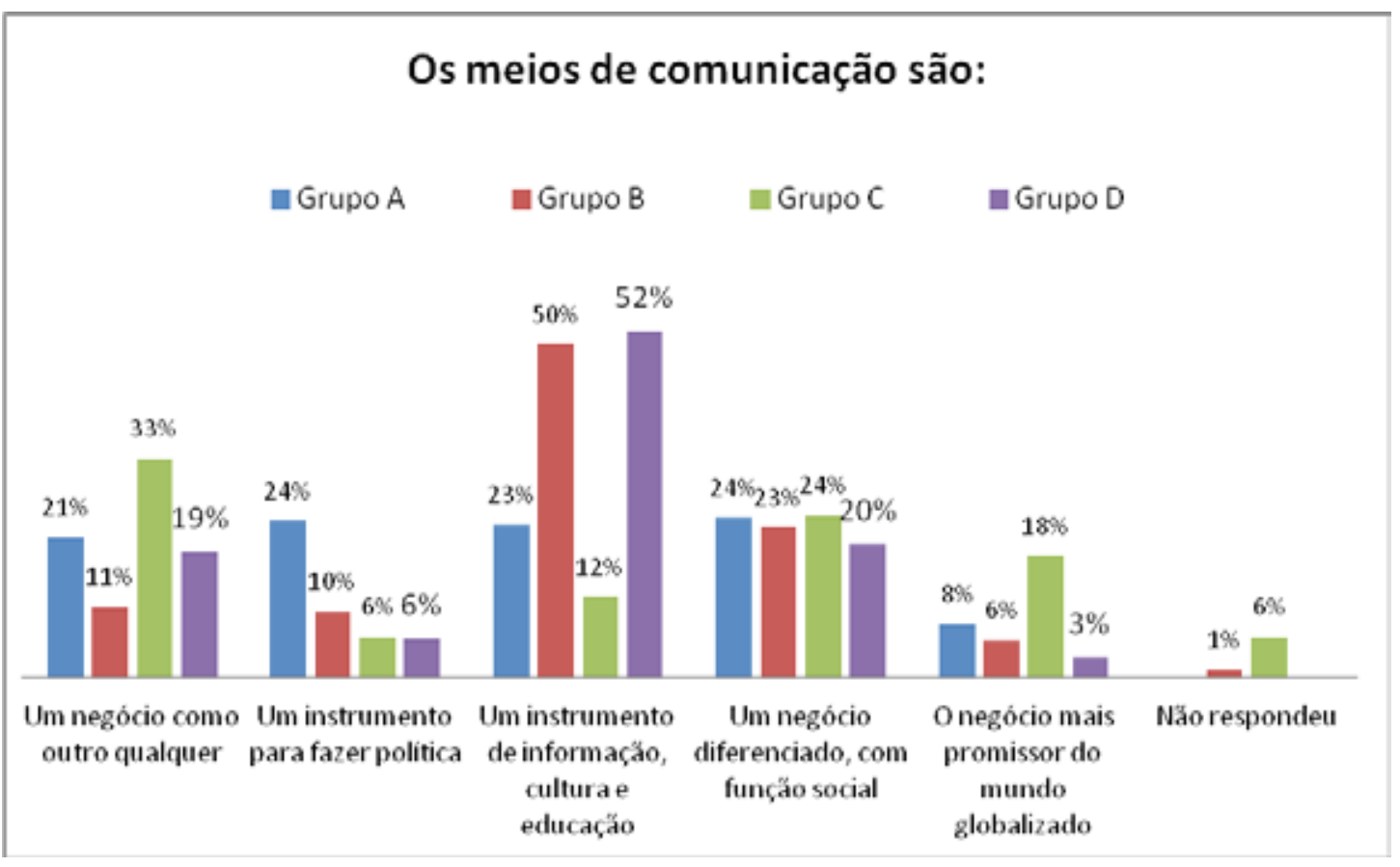


pública fica com apenas $9 \%$ e 11\% das respostas. A percepção da comunicação como negócio é muito acentuada e merece reflexão, embora informação como cultura e educação receba destaque entre as respostas. Portanto, a percepção de que a receita publicitária incide sobremaneira no processo de seu trabalho é resposta majoritária dos jornalistas da pesquisa. Talvez seja esse o motivo para mais de $40 \%$ dos jornalistas que participam da pesquisa afirmarem que às vezes ou não se podem tomar decisões a partir das informações das mídias. Dado gravíssimo.

\section{Nas entrevistas, os sujeitos enunciam a fala sobre 0 trabalho}

Todos os que foram ouvidos e solicitados a responder as perguntas falaram espontaneamente sobre o trabalho (LACOSTE, 1995) e suas experiências, pontos de vista sobre a profissão. Há falas polêmicas. Há relatos de vida que revelam experiências que contextualizam problemas que fazem parte do exercício da profissão no quadro atual das relações do negócio da mídia e do discurso do jornalismo. As dificuldades do mercado de trabalho, as debilidades da formação universitária, as expectativas com relação à profissão e à dedicação ao trabalho desenham as trajetórias pessoais e também compõem 0 quadro real de como se exerce a profissão e as dramáticas da atividade (SCHWARTZ; DURRIVE, 2007) que os jornalistas de carne e osso enfrentam no cotidiano de trabalho. 0s desencontros entre as diferentes gerações, a falta de tempo para a passagem da experiência de um profissional mais velho para o mais jovem e os novos dispositivos da comunicação fazem com que o mundo do trabalho do jornalista se torne um caldeirão de tensões, desafios e conflitos.

A agilidade do acesso aos fatos, eleitos como acontecimento, caracterizam o valor notícia, com isso o tempo torna-se ainda mais um fator de pressão. É um critério fundamental do trabalho jornalístico, sobretudo, para o jornalismo on-line. A notícia em tempo real passa a ditar o valor de noticiabilidade. Os clics da audiência na notícia online vão determinar a próxima pauta.

A distinção entre a fonte, 0 testemunho e a personagem que ilustra a notícia é um complicador a mais para o jornalista. Cada vez mais há mais mediadores entre 0 jornalista e 0 fato. Para alguns a diferença entre o testemunho e o relato jornalístico está embaralhada, para outros há uma relação de solidariedade e colaboração entre a testemunha e 0 jornalista.

Outro aspecto relevante e que tem transformado a relação com o trabalho é o papel das assessorias de comunicação. Hoje elas são necessárias ao processo produtivo. Não se trabalha nas redações das empresas de qualquer veículo de comunicação sem 0 apoio das assessorias. Há brutal profissionalização da área. 0s enunciados do forte e do fraco, do vender e do comprar, da guerrilha e da defesa nomeiam e diferenciam o trabalho 
dos jornalistas assessores e dos jornalistas dos veículos das empresas de comunicação. Mas, na verdade, é impossível trabalhar num veículo de comunicação sem o trabalho anterior do jornalismo de assessoria.

0 ritmo de trabalho, os desafios trazidos pelas novas plataformas e linguagens aumentam a tensão do profissional. Os vínculos contratuais cada vez mais precários, a terceirização e até a quarteirização da produção de conteúdos os chamados trabalhos por projetos - são a realidade no meio profissional. Agenciar o cliente e formatar o produto ao gosto dele passa a fazer parte da prática do jornalista. É o público-alvo/ cliente que conforma 0 enquadramento do produto/notícia.

\section{Os grupos de discussão propiciam 0 confronto de pontos de vista}

Os discursos dos participantes dos grupos de foco (ou grupo de discussão) enunciam uma inquietação que diz respeito: a dar conta da demanda cada vez mais crescente de tarefas e desafios que requerem habilidades para traduzir em conteúdos sobre os mais diversificados temas, dirigidos e oferecidos a públicos, clientes, negócios diferentes, em diversos tipos de plataformas e de linguagens, em situação econômica pouco ou nada estável.

0 tempo saturado para o maior ganho do mercado, o tempo real da informação com valor de circulação é experimentado pelo mais velho e pelo mais jovem.
A métrica dos clics resulta nos perfis de públicoalvo e de linhas editoriais, ditando as regras não só do webjornalismo ou jornalismo on-line, mas de toda a cadeia de produção de veículos, do jornal diário à revista. A métrica dos clics desenha o perfil do público-alvo que o diretor executivo leva para a reunião de pauta. Por isso, a reportagem sobre um problema do ensino público, feita por uma repórter jovem e mais crítica, não pode ir para 0 abre da editoria; lá estará o ranking das escolas de sucesso para 0 vestibular. Também esse nanotempo não é de fato 0 da vida corrente perigosa e sempre um risco, porque ele é medido no relógio do negócio da empresa que não vai fabricar o boneco Ken, namorado da Barbie, e aquela outra pauta sobre meio ambiente vai cair. Velhos e novos dilemas num tempo novo ditando o que fazer e o que é mais importante. Os profissionais mais experientes $\mathrm{e}$ os jovens mais críticos ressentem-se da rapidez com que essas decisões são tomadas. Outros nem percebem por onde escorre os valores notícia e a ética da informação como direito do cidadão.

\section{Conclusões}

A abordagem do binômio comunicação e trabalho mostra-se pertinente e frutífera, porque possibilita entrar no mundo do trabalho via os relatos de quem trabalha e reconstruir por meio deles os fios da rede de relações que se estabelecem. Essa abordagem mostra os processos de comunicação, os problemas e desafios para o exercício profissional, permite entender a amplitude e os limites de pontos de vista que permeiam 0 
universo ideológico daqueles que trabalham, e revela os valores a partir dos quais os jornalistas contam e editam o mundo para a sociedade.

As quatro amostras de jornalistas da pesquisa, com 538 questionários respondidos (dos 3278 que tiveram acesso ao questionário), 20 entrevistas realizadas e dois grupos de discussão, permitem afirmar que as dificuldades da aceleração dos tempos, da variedade de plataformas e da convergência de mídias recrudescem problemas que não são exatamente novos, mas para os quais os jornalistas não conseguem vislumbrar solução. Dizem respeitos às orientações deontológicas da profissão, da ética jornalística no tratamento com as fontes, à visão voltada para 0 interesse público, e não ao público cliente. Tais dificuldades são enunciadas na contraposição: manter os fundamentos ou atender à loucura dos ritmos e demandas do trabalho.

Nas falas dos jornalistas - tanto na entrevista como nos grupos de discussão - o tempo se apresenta como o impostor que impede o exercício crítico e responsável da profissão. É um tempo medido pela resposta-ação cada vez mais intuitiva; refletir, ponderar, analisar e interpretar de maneira a produzir um discurso permeado por diversas vozes, arejado com argumentos a partir de diferentes pontos de vista aparece quase como um devaneio de um período romantizado.

Essa insistência sobre a falta de tempo, do profissional e do público-alvo do produto notícia, leva a concordar com Borges (2008) e apontar que a pressão da notícia em tempo real (ditada pela velocidade do abre e fecha dos mercados financeiros) traz uma mudança no critério de noticiabilidade. A agilidade de acesso aos fatos, eleitos como acontecimento, caracterizam 0 valor notícia. 0 tempo passa a ser mais importante do que 0 fato. 0 fato que não acontece no nanotempo da postagem de atualização não existe.

Entre tantas preocupações e dissonâncias há aqueles que entendem o seu trabalho como uma atividade coletiva, que depende de um conjunto de pessoas, mesmo quando se trabalha sozinho; já outros se veem, mesmo nas redações de grandes veículos de comunicação, como trabalhadores individuais. Os freelancers são os que mais demonstram sofrer com a falta de prescrições e com a insegurança sobre o quê e como ele trabalhará amanhã.

\section{A formação generalista e com forte repertório} humanista é aspecto cada vez mais relevante para a formação do profissional. 0s valores éticos e a responsabilidade com 0 direito à informação precisam ser reforçados como aspectos fundamentais na formação do jornalista, sobretudo, para ajudá-los a enfrentar as injunções da lógica econômica que teima sobrepor-se à lógica do bem-estar das pessoas. 0 direito do cidadão à informação, conforme garantem nossa Constituição e o artigo 19 da Declaração Universal dos Direitos Humanos, é que deve pautar a prática jornalística. 


\section{Referências}

ABREU, Alzira. A modernização da imprensa (19702000). Rio de Janeiro: Zahar, 2002.

BARBOUR, Rosaline. Grupos focais. Porto Alegre: Artemed, 2009. (Coleção pesquisa qualitativas).

BERNARDO, Marcia Espanhol. Trabalho duro, discurso flexível: uma análise das contradições do toyotismo a partir da vivência de trabalhadores. São Paulo: Expressão Popular, 2009.

BOLTANSKI, Luc; CHIAPELLO, Ève. 0 novo espírito do capitalismo. São Paulo: Martins Fontes, 2009.

BORGES, Juliano. Webjornalismo político e a cobertura online das eleições presidenciais de 2002. Revista

Matrizes, São Paulo, ano 2, n. 1, p. 207-225, $2^{\circ}$ semestre 2008.

BOUTET, Josiane. (Éd.) Paroles au travail. Paris: L’Harmattan, 1995.

CASTELLS, Manoel. Communicación y poder. Madri: Alianza, 2009.

DIERKES, M.; HOFMANN, J.; MARZ, L. A evolução tecnológica e a mudança organizacional: estruturas de inovação divergentes. In: OECD. As tecnologias do século XXI: ameaças e desafio de um futuro dinâmico. Lisboa: GEPE, 2000.

FALZON, P. (Ed.) Ergonomia. São Paulo: Blucher, 2007.

FIGAR0, Roseli. Comunicação e trabalho: as mudanças no mundo do trabalho nas empresas de comunicação. (processo 2005/00367-5) São Paulo: Fapesp, 2008. Síntese disponível em: < www.eca.usp.br/ comunicacaoetrabalho $>$ Acesso em: 2-06-2013.

FIGAR0, Roseli (org.) NONATO, Claudia;GROHMANN, Rafael. As mudanças no mundo do trabalho do jornalista. São Paulo: Salta, 2013 (e-book)

FOLCHER, V.; RABARDEL, P. Homens, artefatos, atividades: perspectiva instrumental. In: FALZON, P. (Ed.). Ergonomia. São Paulo: Blucher, 2007.
Gomes, E. Borelli,F. Nazaré, J. Teoria sócio-técnica: resgatando 0 construto à luz da criticidade. REGES Revista Eletrônica de Gestão, Picos, v. 2, n. 2, p. 44-55, maio/ago. 2009. Dospinível em: < http://revistas.ufpi. br/index.php/reges >. Acesso em : 02. jun. 2013. GROHMANN, Rafael. Os discursos dos jornalistas freelancers sobre o trabalho: comunicação, mediações e recepção. Dissertação (Mestrado em Comunicação) - Programa de Pós-graduação em Comunicação, Universidade de São Paulo, São Paulo, 2012.0rientadora: Profa. Dr ${ }^{\mathrm{a}}$ Roseli Fígaro.

HELOANI, José Roberto. Mudanças no mundo do trabalho e impactos na qualidade de vida do jornalista. São Paulo: FGV, 2005. Disponível em: http:// bibliotecadigital.fgv.br/dspace/handle/10438/3098. Acesso em: 02.jun.2013.

JENSEN, K.B.; JANKOWSKI, N.W. Metodologias cualitativas de investigación de masas. Barcelona: Bosch,1993.

LACOSTE, Michèle. Parole, activité, situation. In: BOUTET, Josiane (Éd.). Paroles au travail. Paris: L’Harmattan, 1995.

LANIER, Jaron. Gadget: você não é um aplicativo. São Paulo: Saraiva, 2010.

LEONTIEV, A. Le développement du psychisme. 3.ed. Paris: Editions Sociales, 1976.

LIMA, Cláudia do Carmo Nonato. Comunicação e mundo do trabalho do jornalista : 0 perfil dos jornalistas de São Paulo a partir da reconfiguração dos processos produtivos da informação /São Paulo. $313 \mathrm{f}$. Dissertação (Mestrado em Comunicação) - Escola de Comunicações e Artes, Universidade de São Paulo, São Paulo, 2010. Orientadora: Roseli Fígaro.

MARX, Karl. Manuscritos econômico-filosóficos. Tradução de Artur Morão. Lisboa: Edições 70, 1993.

OLIVESI, Stéphane. La communication au travail: une critique des nouvelles formes de pouvoir dans les entreprises. 2.ed.Grenoble: PUG, 2006. 
PARISER, Eli. 0 filtro invisível: 0 que a internet está escondendo de você. Rio de Janeiro: Zahar, 2012.

SCHWARTZ, Yves; DURRIVE, Louis. Trabalho e

Ergologia. Conversas sobre a atividade humana.

Niteroi : EDUFF, 2007.

SCOLARI, C. Hipermediaciones: elementos para una teoria de la comunicación digital interativa. Barcelona: Gedisa, 2008.

SODRÉ, Muniz. A narração do fato: notas para uma teoria do acontecimento. Petrópolis, RJ: 2009.

VIGOTSKI, L. S. Pensamento e linguagem. 3.ed. São

Paulo: Martins Fontes, 2005. 
Activity of communication and work of journalists

\section{Abstract}

This article discusses the world of work of journalists in Sao Paulo based on the research conducted between 2009 and 2012 by the Centre for Research on Work and Communication, ECA-USP. The research is theoretical and methodological based on the binomial communication and work, that is communication and work are understood as constitutive unity of human activity, able to reveal the values with which society is built. With the methods triangulation of quantitative and qualitative, the research reveals the profile of journalists in Sao Paulo and their views on labor.

\section{Keywords}

Communication and work. Journalist.

Technology. Activity.

\section{Actividad de comunicación y trabajo de los periodistas}

\section{Resumen}

Ese artículo aborda el mundo del trabajo de los periodistas en Sao Paulo basado en la investigación llevada a cabo entre 2009 y 2012 por el Centro para la Investigación sobre Comunicación y Trabajo.La investigación tiene como base teórica y metodológica el binomio comunicación y trabajo, a saber, la comunicación y el trabajo se entiende como unidad constitutiva de la actividad humana, capaz de revelar los valores con los que se construye la sociedad. Con la triangulación de métodos cuantitativos y cualitativos, la investigación revela el perfil de los periodistas en Sao Paulo y sus puntos de vista sobre el trabajo.

\section{Palabras-clave}

Comunicación y trabajo. Periodista.

Tecnología. Actividad. 


\section{Expediente}

A revista E-Compós é a publicação científica em formato eletrônico da Associação Nacional dos Programas de Pós-Graduação em Comunicação (Compós). Lançada em 2004, tem como principal finalidade difundir a produção acadêmica de pesquisadores da área de Comunicação, inseridos em instituições do Brasil e do exterior.
E-COMPÓS I www.e-compos.org.br I E-ISSN 1808-2599

Revista da Associação Nacional dos Programas

de Pós-Graduação em Comunicação.

E-compós, Brasilia, v.16, n.1, jan./abr. 2013

A identificação das edições, a partir de 2008,

passa a ser volume anual com três números.

\section{CONSELHO EDITORIAL}

Afonso Albuquerque, Universidade Federal Fluminense, Brasil Alberto Carlos Augusto Klein, Universidade Estadual de Londrina, Brasil Álvaro Larangeira, Universidade Tuiuti do Paraná, Brasil André Luiz Martins Lemos, Universidade Federal da Bahia, Brasil Ângela Freire Prysthon, Universidade Federal de Pernambuco, Brasil Angela Cristina Salgueiro Marques, Faculdade Cásper Líbero (São Paulo), Brasil Antonio Roberto Chiachiri Filho, Faculdade Cásper Líbero, Brasil Arthur Autran Franco de Sá Neto, Universidade Federal de São Carlos, Brasil Benjamim Picado, Universidade Federal Fluminense, Brasil César Geraldo Guimarães, Universidade Federal de Minas Gerais, Brasil Cristiane Freitas Gutfreind, Pontifícia Universidade Católica do Rio Grande do Sul, Brasil

Denilson Lopes, Universidade Federal do Rio de Janeiro, Brasil Eduardo Peñuela Cañizal, Universidade Paulista, Brasil

Eduardo Vicente, Universidade de São Paulo, Brasil Eneus Trindade, Universidade de São Paulo, Brasil Erick Felinto de Oliveira, Universidade do Estado do Rio de Janeiro, Brasil Florence Dravet, Universidade Católica de Brasília, Brasil Gelson Santana, Universidade Anhembi/Morumbi, Brasil Gislene da Silva, Universidade Federal de Santa Catarina, Brasil Guillermo Orozco Gómez, Universidad de Guadalajara Gustavo Daudt Fischer, Universidade do Vale do Rio dos Sinos, Brasil Hector Ospina, Universidad de Manizales, Colômbia Herom Vargas, Universidade Municipal de São Caetano do Sul, Brasil Inês Vitorino, Universidade Federal do Ceará, Brasil Jay David Bolter, Georgia Institute of Technology Jeder Silveira Janotti Junior, Universidade Federal de Pernambuco, Brasil John DH Downing, University of Texas at Austin, Estados Unidos José Afonso da Silva Junior, Universidade Federal de Pernambuco, Brasil José Carlos Rodrigues, Pontifícia Universidade Católica do Rio de Janeiro, Brasil José Luiz Aidar Prado, Pontifícia Universidade Católica de São Paulo, Brasil Kelly Cristina de Souza Prudêncio, Universidade Federal do Paraná, Brasil.
Laan Mendes Barros, Universidade Metodista de São Paulo, Brasil Lance Strate, Fordham University, USA, Estados Unidos Lorraine Leu, University of Bristol, Grã-Bretanha Lucia Leão, Pontifícia Universidade Católica de São Paulo, Brasil Malena Segura Contrera, Universidade Paulista, Brasil

Márcio de Vasconcellos Serelle, Pontifícia Universidade Católica de Minas Gerais, Brasil

Maria Aparecida Baccega, Universidade de São Paulo e Escola Superior de Propaganda e Marketing, Brasil

Maria Ataide Malcher, Universidade Federal do Pará, Brasil

Maria das Graças Pinto Coelho, Universidade Federal do Rio Grande do Norte, Brasil Maria Immacolata Vassallo de Lopes, Universidade de São Paulo, Brasil Maria Luiza Martins de Mendonça, Universidade Federal de Goiás, Brasil Mauro de Souza Ventura, Universidade Estadual Paulista, Brasil Mauro Pereira Porto, Tulane University, Estados Unidos Mirna Feitoza Pereira, Universidade Federal do Amazonas, Brasil Nilda Aparecida Jacks, Universidade Federal do Rio Grande do Sul, Brasil Osvando J. de Morais, Universidade de Sorocaba, Brasil Potiguara Mendes Silveira Jr, Universidade Federal de Juiz de Fora, Brasil Renato Cordeiro Gomes, Pontifícia Universidade Católica do Rio de Janeiro, Brasil Robert K Logan, University of Toronto, Canadá

Ronaldo George Helal, Universidade do Estado do Rio de Janeiro, Brasil Rose Melo Rocha, Escola Superior de Propaganda e Marketing, Brasil Rossana Reguillo, Instituto de Estudos Superiores do Ocidente, Mexico Rousiley Celi Moreira Maia, Universidade Federal de Minas Gerais, Brasil Sebastião Guilherme Albano da Costa, Universidade Federal do Rio Grande do Norte, Brasil

Simone Maria Andrade Pereira de Sá, Universidade Federal Fluminense, Brasil Tiago Quiroga Fausto Neto, Universidade de Brasília, Brasil Suzete Venturelli, Universidade de Brasília, Brasil Valerio Fuenzalida Fernández, Puc-Chile, Chile

Veneza Mayora Ronsini, Universidade Federal de Santa Maria, Brasil Vera Regina Veiga França, Universidade Federal de Minas Gerais, Brasil

\section{COMISSÃO EDITORIAL}

Adriana Braga I Pontifícia Universidade Católica do Rio de Janeiro, Brasil

Felipe Costa Trotta I Universidade Federal Fluminense, Brasil

CONSULTORES AD HOC

Bruno Campanella, Universidade Federal Fluminense, Brasil

Christa Berger, Universidade do Vale do Rio dos Sinos, Brasil

Edison Gastaldo, Universidade Federal Rural do Rio de Janeiro, Brasil

José Luiz Braga, Universidade do Vale do Rio dos Sinos, Brasil

\section{EDIÇÃO DE TEXTO E RESUMOS I Susane Barros}

SECRETÁRIA EXECUTIVA I Juliana Depiné

EDITORACã̃ ELETRÔNICA I Roka Estúdio
COMPóS I www.compos.org.br

Associação Nacional dos Programas de Pós-Graduação em Comunicação

Presidente

Julio Pinto

Pontifícia Universidade Católica de Minas Gerais, Brasil juliopinto@pucminas.br

Vice-presidente

Itania Maria Mota Gomes

Universidade Federal da Bahia, Brasil

itania@ufba.br

Secretária-Geral

Inês Vitorino

Universidade Federal do Ceará, Brasil

inesvic@gmail.com 